\title{
2512. Influence of different materials for artificial auditory ossicle on the dynamic characteristics of human ear and research on hearing recovery
}

\author{
Xiao-ping Jiang ${ }^{1}$, Cheng-hua $\mathrm{Li}^{2}$, Hao Ding ${ }^{3}$, Jing Sun ${ }^{4}$, Jie-di Sun ${ }^{5}$ \\ 1,2,3,4 The College of Electronics and Information Engineering, Hubei Key Laboratory of Intelligent \\ Wireless Communications, South-Central University for Nationalities, Wuhan 430074, China \\ ${ }^{5}$ School of Information Science and Engineering, Yanshan University, QinHuangDao 066004, China \\ ${ }^{2}$ Corresponding author \\ E-mail: ${ }^{1}$ arkage@qq.com, ${ }^{2}$ tylch@163.com, ${ }^{3}$ dinghaoceie@163.com, ${ }^{4}$ sunjing528@163.com, \\ 5sunjiedi@163.com
}

Received 16 November 2016; received in revised form 23 May 2017; accepted 25 May 2017 DOI https://doi.org/10.21595/jve.2017.18026

Check for updates

\begin{abstract}
This paper used PATRAN/NASTRAN software to establish a three-dimensional finite element model of human ear and conduct dynamic simulation of hearing system. The correctness of the finite element model was verified through analyzing the tympanic membrane displacement of normal human ear under the sound pressure of $80 \mathrm{~dB}$ and comparing with the experimental data. Based on the verified model, this paper qualitatively and quantitatively studied and compared the influence of artificial auditory ossicle with 7 kinds of common materials (titanium, stainless steel, teflon, porous polyethylene, alumina ceramic, EH composites and hydroxylapatite ceramics) on the sound conduction of human ear and the effect of postoperative hearing recovery under different sound pressures $(50 \mathrm{~dB}, 80 \mathrm{~dB}, 105 \mathrm{~dB}$ and $120 \mathrm{~dB})$ at 100-10000 Hz. Results showed that the hearing recovery of human ear had the same effect after replacing artificial auditory ossicle under different sound pressures with different frequency. At different frequencies with the same sound pressure, the postoperative hearing of human ear had different effects after replacing different materials of artificial auditory ossicle. Artificial auditory ossicle of hydroxylapatite ceramics, stainless steel and alumina ceramic had better effect on sound conduction at low frequencies, while artificial auditory ossicle of porous polyethylene and teflon had better effect on sound conduction at high frequencies. Under different sound pressures, replacing artificial auditory ossicle with 7 kinds of common materials showed little difference in the hearing recovery of human ear at each frequency band and had a stable influence on the sound conduction of human ear.
\end{abstract}

Keywords: human ear, artificial auditory ossicle, dynamics, different materials.

\section{Introduction}

Hearing medicine is a science which studies hearing function and rehabilitation of hearing impairment in a physiological and pathological state. Its foundation is the anatomy and physiology of ear and knowledge related to mechanics, acoustics and electromagnetics. Conduction deafness will be generated when the transmission of sound wave is hindered by outer ear or middle ear lesions in hearing system.

People's research on the vibration transmission of sound pressure in human ear is limited due to dense structure and complex boundary conditions of human ear. In traditional methods, anatomy is used to observe and study the force transfer behavior of middle ear. Artificial excitation is mostly applied to tympanic membrane to observe the mechanical data at the key position of middle ear and know about the sound conduction mechanism of normal or pathological middle ear [1-5]. With the improvement of imagining technique, people have used CT (computed tomography) or MRI (magnetic resonance imaging) to obtain the anatomical data of middle ear in a state of human physiology, build a solid model with expanding proportion according to the obtained data and make the experiment to be observed $[6,7]$, which also provides a basis for further studying the mechanical behavior of middle ear in the state of active physiology. In recent 
years, some scholars have started to use the analytic method to study the mechanical behavior of middle ear $[8,9]$.

The mentioned methods have great limitations. Due to the numerical simulation method of high-performance computer and the progress of imagining, scholars have started to apply mature finite element analysis software to establish the finite element model, analyze the dynamics of middle ear and obtain a series of achievements in recent years, which greatly promotes the research on the structural mechanical behavior of middle ear. Precise numerical model of human ear is beneficial to simulating and predicting the dynamic behavior of human middle ear more accurately. For this reason, scholars start to look for different methods of finite element model to establish more accurately structural models of human ear.

The constant accuracy and completeness of the finite element model and further research of numerous scholars on the material property and constitutive relationship of various tissues of human ear $[10,11]$ provide a lot of valuable information for studying human ear. The nonlinear constitutive relationship of some structures of human ear also starts to be applied to the finite element model. Research on human ear through numerical method is no longer limited to simulating and verifying tympanic membrane, the vibration mode of ossicular chain or other dynamic parameters of normal ear.

With the rapid development of material science, more materials have been effectively applied to the research of life science. New materials are an important component of high and new technology and also an important pillar and breakthrough of developing high and new technology. At present, biological materials applied to artificial auditory ossicle are mainly metal materials, ceramic materials and high polymer materials. Artificial auditory ossicle can be made of various biological materials. Shen [12-15] has introduced the preparation and clinical effect of common materials (alumina ceramic, EH type composites, hydroxyapatite ceramics, titanium and porous polyethylene) of artificial auditory ossicle. Zhang [16] compared the complication incidence rate and postoperative hearing improvement of artificial auditory ossicle with bioceramics and titanium after hearing reconstruction tympanum. With the rapid development of otomicrosurgery and the promotion of tympanum, research on the materials of ossicular chain reconstruction has been gradually thorough. Zeng [17] analyzed the material properties of several ossicular chain reconstruction and their advantages and disadvantages in the process of application. This paper used PATRAN/NASTRAN software to reconstruct a three-dimensional finite element model of human ear, conduct dynamic simulation of hearing system and qualitatively and quantitatively study the influence of different materials of PORP on the hearing recovery of human ear.

\section{Establishment of the finite element model}

\subsection{The finite element model}

This paper established a complete three-dimensional finite element model of human ear through PATRAN. The model contained outer ear, middle ear and spiral inner ear. The complete finite element model of human ear was shown in Fig. 1. Model parameters, mesh division and boundary conditions referred to the published papers [18-23].

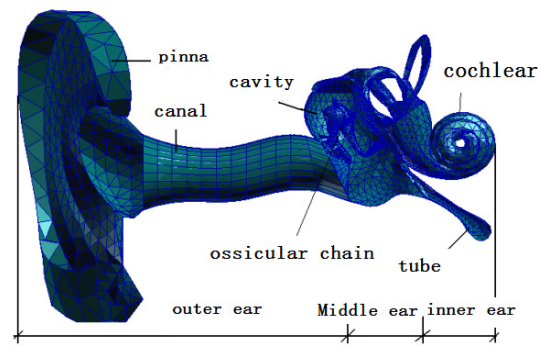

Fig. 1. A complete finite element model of human ear 


\subsection{Finite element model of artificial auditory ossicle}

The dimension data of artificial auditory ossicle came from product instructions of Medtronic Xomed Company. Model of artificial auditory ossicle is as follows: $S I D=1.17 \mathrm{~mm}$, $H D=4.0 \mathrm{~mm}, L=4.75 \mathrm{~mm}$, as shown in Fig. 2 .

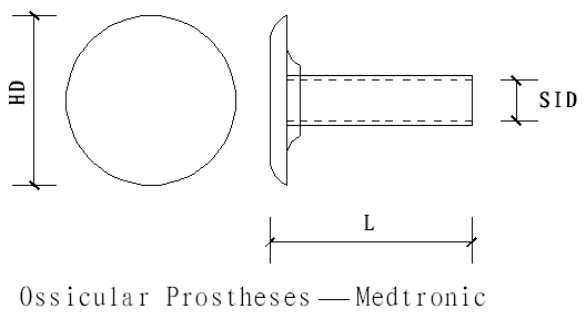

Fig. 2. Dimension of artificial auditory ossicle

PATRAN software was used to establish a model and divide meshes. The finite element model contained 1479 nodes, 950 eight-node hexahedral elements and 100 six-node pentahedral elements whose attribute was defined as solid. The top tray of artificial auditory ossicle was connected to tympanic membrane and both ends of artificial auditory ossicle were connected to stapes head, as shown in Fig. 3 to Fig. 5.

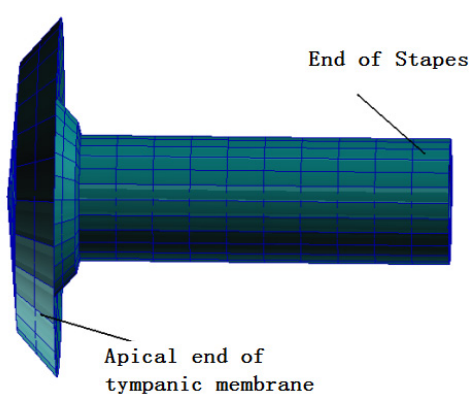

Fig. 3. Finite element model of artificial auditory ossicle

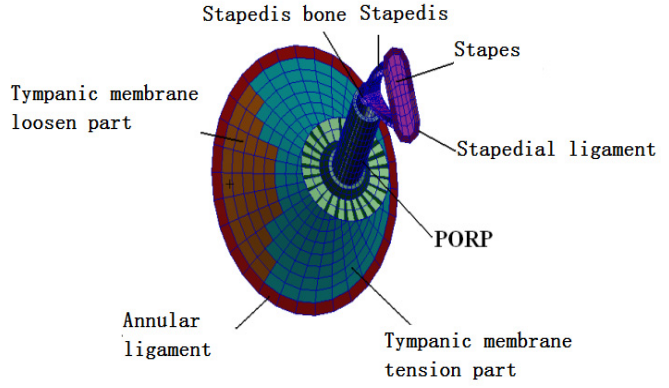

Fig. 4. Finite element model of middle ear after replacing artificial auditory ossicle

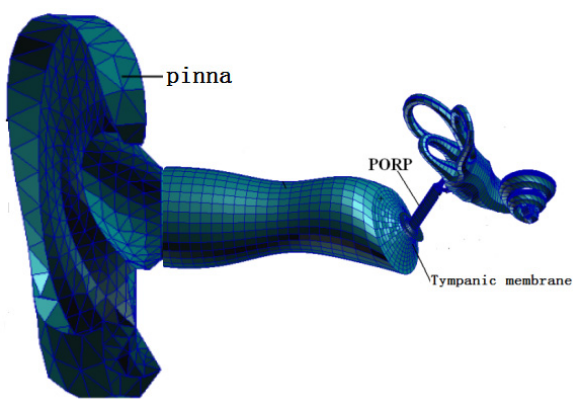

Fig. 5. Finite element model of total ear after replacing artificial auditory ossicle

\section{Model verification and analysis of middle ear lesions}

With considering the influence of external auditory canal, the sound pressure $80 \mathrm{~dB}(0.2 \mathrm{~Pa})$ was applied to the entrance of external auditory canal to analyze frequency response, obtain frequency-response curve of tympanic membrane and compare with the experimental data of Ferris, Kelly, Huber, Nsihihara \& Goode et al. [3, 24-26], as shown in Fig. 6. The displacement 
contour of tympanic membrane under the characteristic frequency was shown in Fig. 7.

As can be seen from Fig. 6 and Fig. 7, it could be shown that tympanic membrane displacement-frequency response curve obtained by this paper was between the curves of Huber and Kelly at $100 \mathrm{~Hz}-10000 \mathrm{~Hz}$. through experiments. At $100 \mathrm{~Hz}-3000 \mathrm{~Hz}$, the result of numerical simulation was basically consistent with the experimental data of Nsihihara \& Goode et al. At $4000 \mathrm{~Hz}-10000 \mathrm{~Hz}$, the result of numerical simulation was basically consistent with the experimental data of Ferris and Kelly et al.

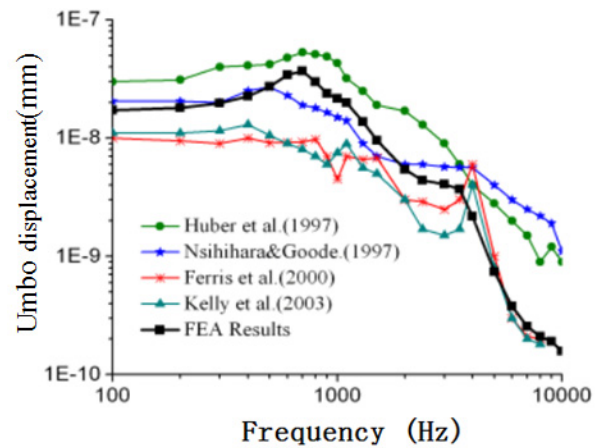

Fig. 6. Comparison of umbo displacement between the proposed model and the experiment $(80 \mathrm{~dB})$

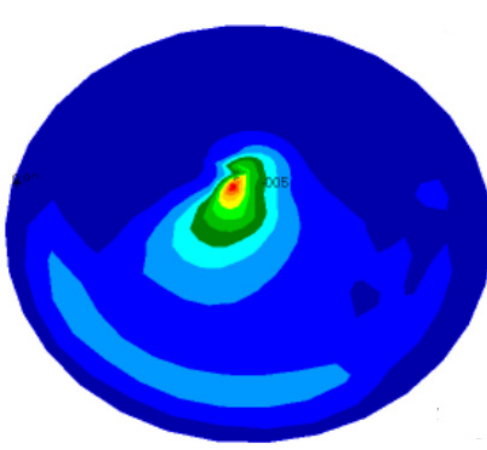

Fig. 7. Displacement contour of tympanic membrane

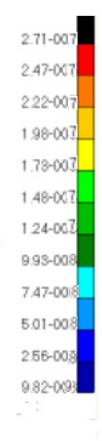

Based on the verified finite element model, this paper simulated the dynamic response curve of tympanum with lesions. Through referring to the method proposed by Dai [27], 100 times of normal status was seemed as the elastic modulus with sclerodesmia. 2663 Tet 4 ossification elements were arranged around the junction of malleus head, body of incus, malleus suspensory ligament and incus suspensory ligament. $490 \mathrm{MPa}$ was selected as material property to obtain stapes displacement-frequency response data after lesions in the case of applying the sound pressure $50 \mathrm{~dB}, 80 \mathrm{~dB}$ and $105 \mathrm{~dB}$ to the entrance of external auditory canal. As shown from Table 1 to Table 3, the vibration displacement of stapes had the same order of magnitude under the excitation of the same sound pressure. Vibration displacement gradually decreased with the increase of frequencies. In addition, vibration displacement increased with the increase of the sound pressure.

Table 1. Vibration displacement and velocity of stapes with lesions $(50 \mathrm{~dB})$

\begin{tabular}{|c|c|c|c|}
\hline Frequency $(\mathrm{Hz})$ & Displacement $(\mathrm{mm})$ & Frequency $(\mathrm{Hz})$ & Displacement $(\mathrm{mm})$ \\
\hline 100 & $3.2 \mathrm{E}-08$ & 2500 & $4 \mathrm{E}-09$ \\
\hline 200 & $3.3 \mathrm{E}-08$ & 3000 & $4 \mathrm{E}-09$ \\
\hline 400 & $3.8 \mathrm{E}-08$ & 4000 & $7 \mathrm{E}-09$ \\
\hline 600 & $5 \mathrm{E}-08$ & 5000 & $2 \mathrm{E}-09$ \\
\hline 800 & $7.5 \mathrm{E}-08$ & 6000 & $7 \mathrm{E}-10$ \\
\hline 1000 & $1.05 \mathrm{E}-07$ & 7000 & $4 \mathrm{E}-10$ \\
\hline 1500 & $7.2 \mathrm{E}-08$ & 10000 & $2 \mathrm{E}-10$ \\
\hline
\end{tabular}

Table 2. Vibration displacement and velocity of stapes with lesions $(80 \mathrm{~dB})$

\begin{tabular}{|c|c|c|c|}
\hline Frequency $(\mathrm{Hz})$ & Displacement $(\mathrm{mm})$ & Frequency $(\mathrm{Hz})$ & Displacement $(\mathrm{mm})$ \\
\hline 100 & $1.013 \mathrm{E}-06$ & 2500 & $1.29 \mathrm{E}-07$ \\
\hline 200 & $1.049 \mathrm{E}-06$ & 3000 & $1.18 \mathrm{E}-07$ \\
\hline 400 & $1.216 \mathrm{E}-06$ & 4000 & $2.16 \mathrm{E}-07$ \\
\hline 600 & $1.589 \mathrm{E}-06$ & 5000 & $6 \mathrm{E}-08$ \\
\hline 800 & $2.374 \mathrm{E}-06$ & 6000 & $2.4 \mathrm{E}-08$ \\
\hline 1000 & $3.316 \mathrm{E}-06$ & 7000 & $1.5 \mathrm{E}-08$ \\
\hline 1500 & $2.267 \mathrm{E}-06$ & 10000 & $9 \mathrm{E}-09$ \\
\hline
\end{tabular}


Table 3. Vibration displacement and velocity of stapes with lesions (105 dB)

\begin{tabular}{|c|c|c|c|}
\hline Frequency $(\mathrm{Hz})$ & Displacement $(\mathrm{mm})$ & Frequency $(\mathrm{Hz})$ & Displacement $(\mathrm{mm})$ \\
\hline 100 & $1.8023 \mathrm{E}-05$ & 2500 & $2.29 \mathrm{E}-06$ \\
\hline 200 & $1.8674 \mathrm{E}-05$ & 3000 & $2.095 \mathrm{E}-06$ \\
\hline 400 & $2.165 \mathrm{E}-05$ & 4000 & $3.838 \mathrm{E}-06$ \\
\hline 600 & $2.829 \mathrm{E}-05$ & 5000 & $1.061 \mathrm{E}-06$ \\
\hline 800 & $4.2259 \mathrm{E}-05$ & 6000 & $4.27 \mathrm{E}-07$ \\
\hline 1000 & $5.9032 \mathrm{E}-05$ & 7000 & $2.63 \mathrm{E}-07$ \\
\hline 1500 & $4.0358 \mathrm{E}-05$ & 10000 & $1.59 \mathrm{E}-07$ \\
\hline \multicolumn{4}{|l}{} \\
\hline
\end{tabular}

\section{Numerical analysis on artificial auditory ossicle with different materials}

This paper mainly started from the mechanical property of biological materials and studied the influence of artificial auditory ossicles with different materials on the mechanical mechanism of sound conduction of human ear. The properties of artificial auditory ossicle with different materials were shown in Table 4. Biocompatibility needed to be considered when biological materials were applied to the human body, which might involve problems in other disciplinary fields except for mechanics. It will be further analyzed in our future studies.

Table 4. Material properties of artificial auditory ossicle with different materials

\begin{tabular}{|c|c|c|}
\hline PORP material name & Elastic modulus $(\mathrm{GPa})$ & Poisson's ratio \\
\hline Titanium & 116 & 0.33 \\
\hline Stainless steel & 200 & 0.3 \\
\hline Teflon & 0.5 & 0.3 \\
\hline Porous polyethylene & 0.7 & 0.3 \\
\hline Alumina ceramic & 375 & 0.22 \\
\hline EH type composites & 17 & 0.3 \\
\hline Hydroxyapatite ceramics & 155 & 0.3 \\
\hline
\end{tabular}

\subsection{Analysis on dynamic characteristics}

The sound pressure $80 \mathrm{~dB}(0.2 \mathrm{~Pa})$ was applied to the entrance of external auditory canal to simulate the hearing system of the finite element model at $100 \mathrm{~Hz}-10000 \mathrm{~Hz}$ after replacing PORP with 7 kinds of materials (materials were shown in Table 4 for the convenience of expression, 7 kinds of materials were respectively defined as P1 to P7), and the frequency-response curve of stapes displacement and velocity was analyzed and obtained, as shown in Fig. 8 to Fig. 9. The finite element model of this paper simulated the displacement contour of total ear and middle ear at the characteristic frequency of normal conditions, as shown in Fig. 10.

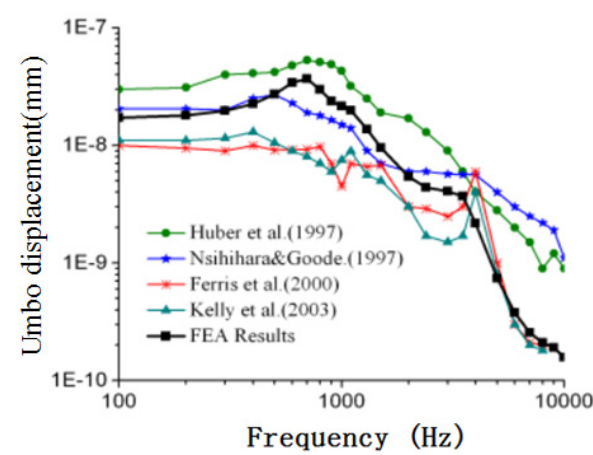

Fig. 8. Frequency-response curve of stapes displacement after replacing PORP $(80 \mathrm{~dB})$

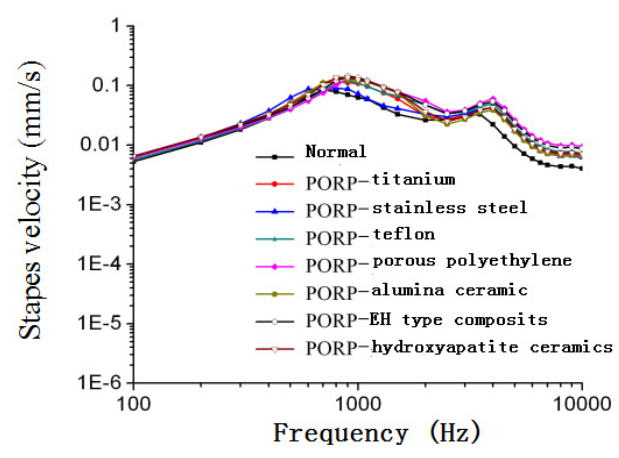

Fig. 9. Frequency-response curve of stapes velocity after replacing PORP $(80 \mathrm{~dB})$

As shown from Fig. 8 and Fig. 9, the frequency-response curve of stapes displacement and 
velocity of PORP with different materials was close to the hearing curve of normal human ear. Patients with replacing PORP had good effect of postoperative hearing recovery. Hearing recovery in the paper meant that the hearing value (the relative displacement of stapes and umbo) after applying artificial auditory ossicles with different materials subtracted the hearing value (the relative displacement of stapes and umbo) before applying artificial auditory ossicles with different materials. In addition, the replacement of PORP had a significant effect on hearing recovery in short term.

Fig. 10 showed the regulation of pressure distribution of external auditory canal. It could be noticed from different colors of the figure that pressure gradually increased from the entrance of external auditory canal to tympanic membrane. At the tympanic membrane, the pressure of external auditory canal was the largest. Thus, it could be seen that external auditory canal played a role in increasing pressure.

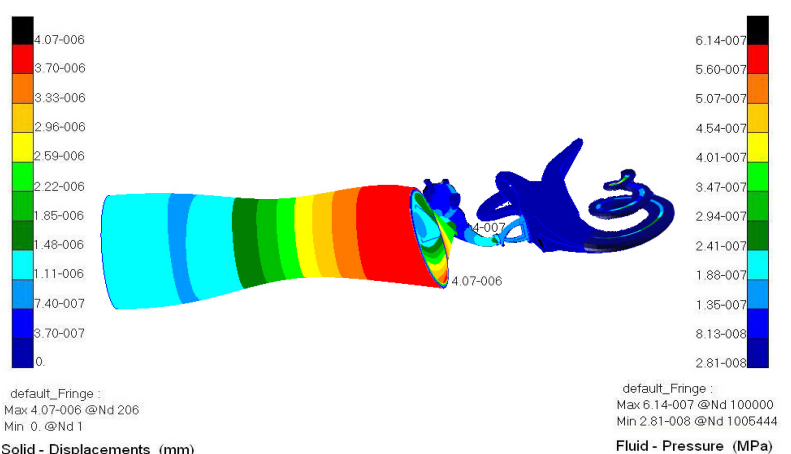

a)

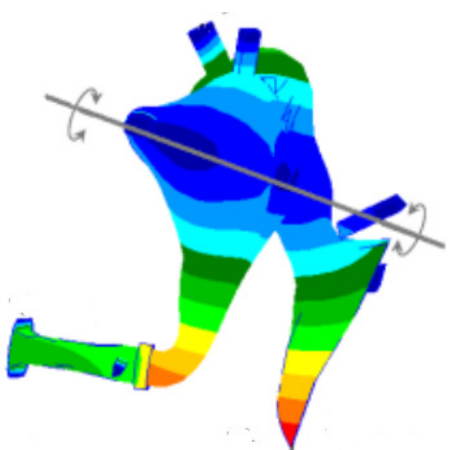

b)

Fig. 10. a) Sound pressure and displacement contour of total ear, b) displacement contour of middle ear

\subsection{Analysis on hearing recovery}

Through computing and comparing the displacement of PORP with 7 kinds of different materials and the data of lesions in Table 2, the hearing recovery of PORP with different materials in the case of relative lesions after operation was obtained, as shown in Fig. 11. The envelope diagram of hearing recovery was made to conduct a quantitative analysis on the situation of postoperative hearing improvement after replacing PORP, as shown in Fig. 12.

As shown from Fig. 11 and Fig. 12, each material had different effect on postoperative hearing recovery at different frequency bands. At the frequency band from $100 \mathrm{~Hz}-10000 \mathrm{~Hz}$, the envelop of hearing recovery of human ear after replacing PORP with different materials in the short run was discussed, as shown in Table 5 and Table 6.

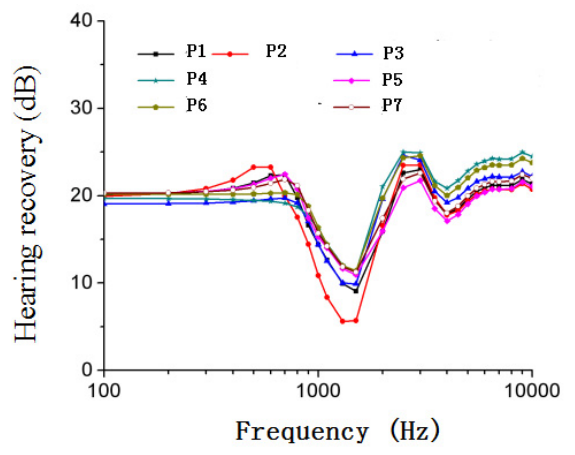

Fig. 11. Diagram for hearing recovery after replacing PORP with different materials $(80 \mathrm{~dB})$

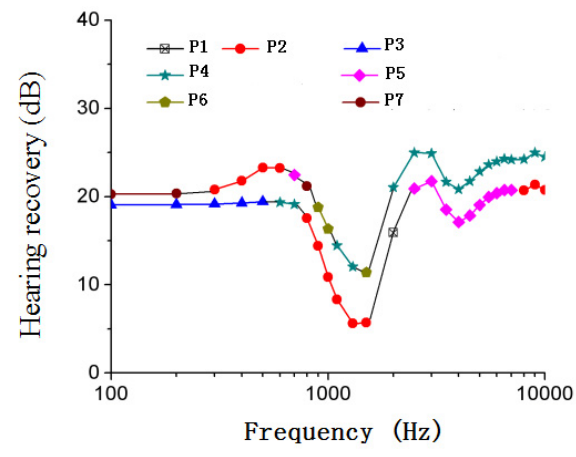

Fig. 12. Envelop diagram for hearing recovery after replacing PORP with different materials $(80 \mathrm{~dB})$ 
Table 5. The maximum value of hearing recovery in short term after replacing PORP

\begin{tabular}{|c|c|c|}
\hline Frequency $(\mathrm{Hz})$ & Material with the maximum hearing recovery & The maximum interval $(\mathrm{dB})$ \\
\hline $100-200$ & Hydroxyapatite ceramics & $20.27-20.33$ \\
\hline $200-600$ & Stainless steel & $20.33-23.26$ \\
\hline $600-700$ & Alumina ceramic & $22.46-23.25$ \\
\hline $700-800$ & Hydroxyapatite ceramics & $21.17-22.46$ \\
\hline $800-1000$ & EH type composites & $16.34-21.17$ \\
\hline $1000-10000$ & Porous polyethylene & $12.04-25.00$ \\
\hline
\end{tabular}

Table 6. The minimum value of hearing recovery in short term after replacing PORP

\begin{tabular}{|c|c|c|}
\hline Frequency $(\mathrm{Hz})$ & Material with the minimum hearing recovery & The minimum interval $(\mathrm{dB})$ \\
\hline $100-500$ & Teflon & $19.06-19.42$ \\
\hline $500-700$ & Porous polyethylene & $19.14-19.42$ \\
\hline $700-1500$ & Stainless steel & $5.62-19.14$ \\
\hline 2000 & Titanium & 15.90 \\
\hline $2500-8000$ & Alumina ceramic & $17.10-20.70$ \\
\hline $8000-10000$ & Stainless steel & $20.70-21.36$ \\
\hline
\end{tabular}

It could be clearly seen from Table 5, Table 6 and Fig. 12 that artificial auditory ossicle of hydroxyapatite ceramics, stainless steel, alumina ceramic and EH type composites had the maximum hearing recovery at the low frequency band, namely $16.34 \mathrm{~dB}$ to $23.26 \mathrm{~dB}$, and reached the maximum value about $23.26 \mathrm{~dB}$ around $500 \mathrm{~Hz}$. However, artificial auditory ossicle with teflon and porous polyethylene had the minimum hearing recovery, about $19.06 \mathrm{~dB}$ to $19.42 \mathrm{~dB}$ at the low frequency band. At the high frequency band, artificial auditory ossicle with porous polyethylene improved human ear hearing most, namely $12.04 \mathrm{~dB}$ to $25.00 \mathrm{~dB}$, and reached the maximum value $25 \mathrm{~dB}$ around $3000 \mathrm{~Hz}$. Artificial auditory ossicle with alumina ceramic and stainless steel had the minimum hearing recovery at the high frequency band, about $17.10 \mathrm{~dB}$ to $21.36 \mathrm{~dB}$. Only postoperative hearing recovery in short term could be obtained through the finite element analysis. In addition, the PORP with different materials had a good effect on the hearing recovery of human ear in short term. Artificial auditory ossicle with hydroxyapatite ceramics, stainless steel and alumina ceramic had a good effect on sound conduction at the low frequency band. Artificial auditory ossicle with porous polyethylene and teflon had a good effect on sound conduction at the high frequency band. With considering hearing effect in long term, titanium, teflon and hydroxyapatite ceramics which had the best biocompatibility had better hearing effect.

\section{Analysis on PORP with different materials under different sound pressures}

\subsection{Analysis on PORP with different materials under different sound pressures}

Sound pressures including $50 \mathrm{~dB}(0.00632 \mathrm{~Pa}), 105 \mathrm{~dB}(3.56 \mathrm{~Pa})$ and $120 \mathrm{~d} \mathrm{~B}(20 \mathrm{~Pa})$ were respectively applied to the entrance of external auditory canal to conduct analogue simulation of total ear model after replacing PORP with different materials at $100 \mathrm{~Hz}-10000 \mathrm{~Hz}$. Through simulation analysis, frequency-response curve of stapes displacement and velocity was obtained, as shown from Figs. 13-18.

velocity under different sound pressures $(50 \mathrm{~dB}, 80 \mathrm{~dB}, 105 \mathrm{~dB}$ and $120 \mathrm{~dB})$ after replacing PORP with different materials was close to the hearing curve of normal human ear. Patients with replacing artificial auditory ossicle had a good effect on postoperative hearing recovery in short term.

\subsection{Analysis on hearing recovery}

Through computing and comparing the curve from Figs. 13-18 after replacing PORP with different materials and data with lesions in Table 1 and Table 3, hearing recovery of relative 
lesions after replacing PORP was obtained.

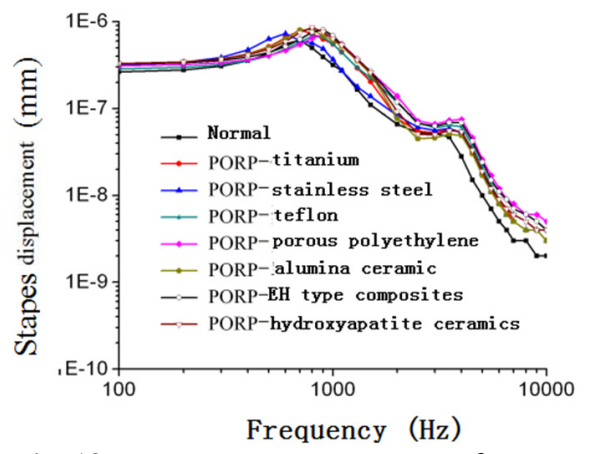

Fig. 13. Frequency-response curve of stapes displacement after replacing PORP $(50 \mathrm{~dB})$

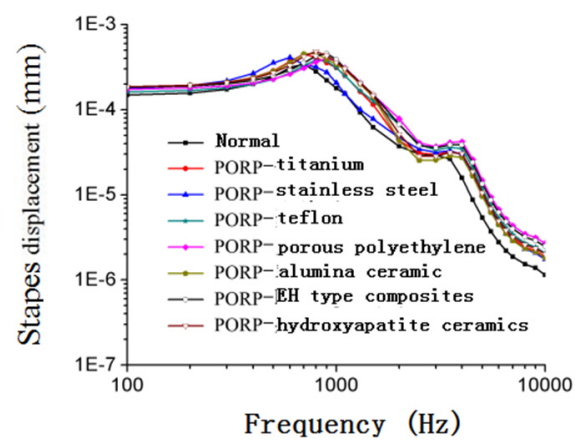

Fig. 15. Frequency-response curve of stapes displacement after replacing PORP (105 dB)

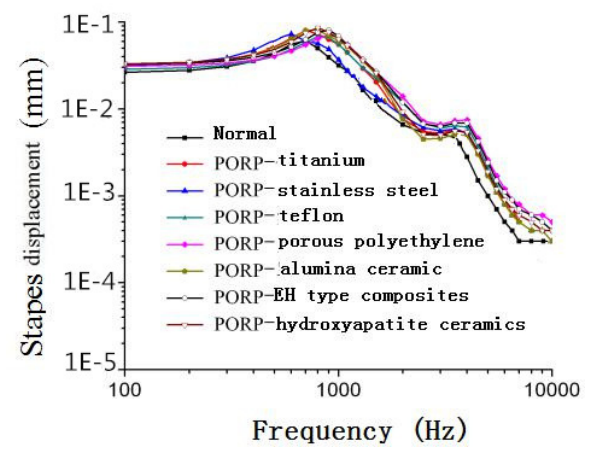

Fig. 17. Frequency-response curve of stapes displacement after replacing PORP (120 dB)

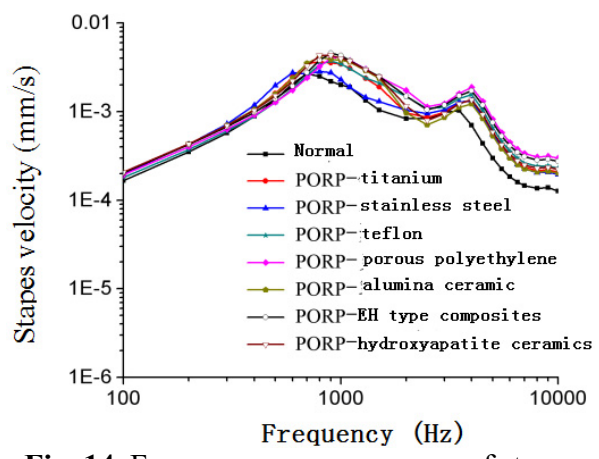

Fig. 14. Frequency-response curve of stapes velocity after replacing PORP $(50 \mathrm{~dB})$

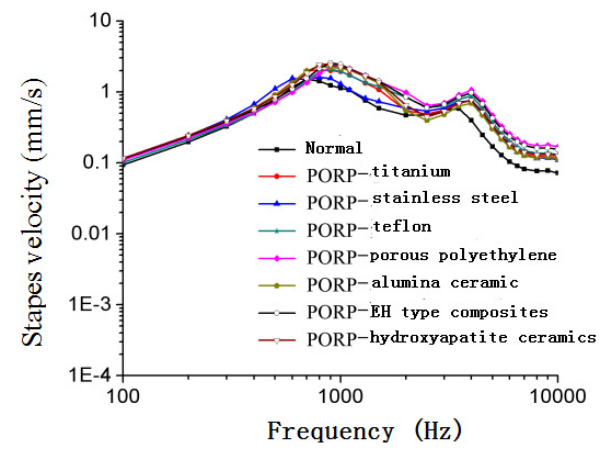

Fig. 16. Frequency-response curve of stapes velocity after replacing PORP (105 dB)

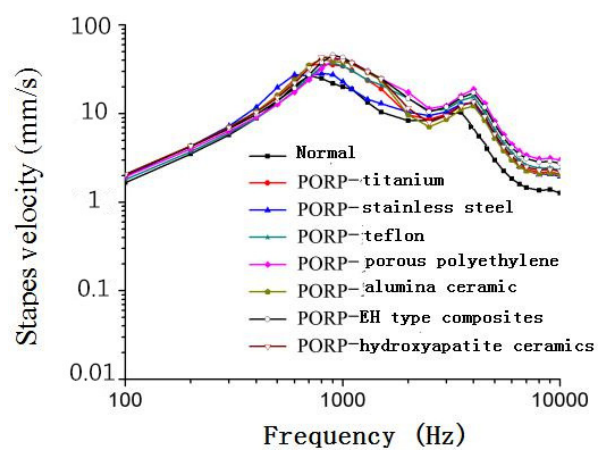

Fig. 18. Frequency-response curve of stapes velocity after replacing PORP (120 dB)

As shown from Fig. 9 to Fig. 18, the frequency-response curve of stapes displacement and

The envelope diagram of hearing recovery was made in order to conduct a quantitative analysis on the situation of hearing improvement after replacing different materials, as shown in Fig. 19 and Fig. 24.

As displayed from Fig. 19 to Fig. 24, various materials had different postoperative hearing recovery at different frequency bands. The extremum of postoperative hearing recovery of human ear after replacing artificial auditory ossicle in short term at $100 \mathrm{~Hz}-10000 \mathrm{~Hz}$ was discussed. The vibration response at $120 \mathrm{~dB}$ SPL of the whole ear system after replacing PROP was also shown 
in Fig. 25. The specific hearing recovery values under different sound pressure levels $(50 \mathrm{~dB}, 80 \mathrm{~dB}, 105 \mathrm{~dB}$ and $120 \mathrm{~dB})$ were shown in Table 7 and Table 8.

As shown from Table 7 and Table 8, the hearing recovery values of human ear after replacing artificial auditory ossicle with different materials had little difference at each frequency band under different sound pressure levels $(50 \mathrm{~dB}, 80 \mathrm{~dB}, 105 \mathrm{~dB}$ and $120 \mathrm{~dB})$, which indicated that artificial auditory ossicle with different materials had a stable influence on the sound conduction of human ear under the excitation of different sound pressures. At low frequencies, artificial auditory ossicle with hydroxyapatite ceramics, stainless steel, alumina ceramic and EH type composites had the maximum hearing recovery, namely $16.33 \mathrm{~dB}$ to $23.26 \mathrm{~dB}$, and reached the maximum value about $23.26 \mathrm{~dB}$ around $500 \mathrm{~Hz}$.
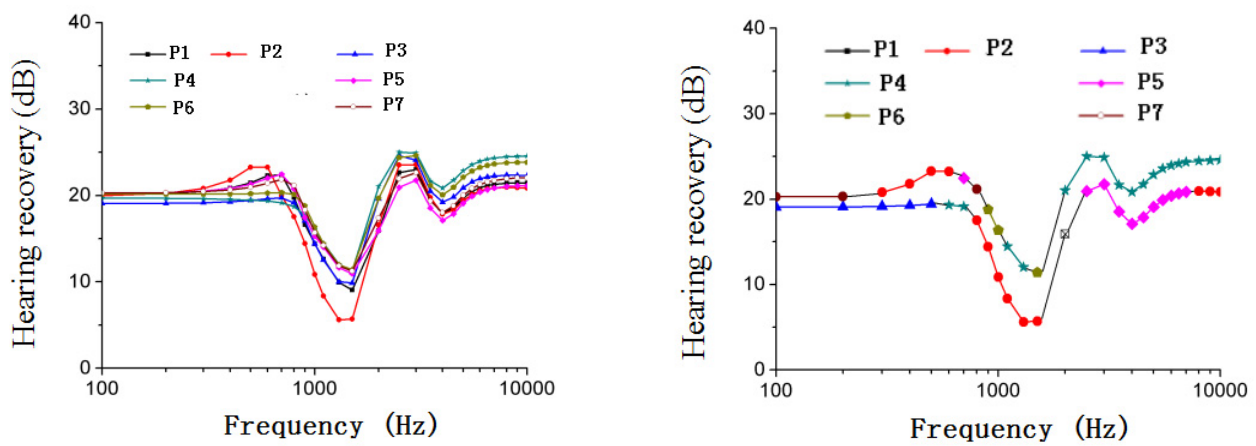

Fig. 19. Diagram for hearing recovery after replacing Fig. 20. Envelop diagram for hearing recovery after PORP with different materials $(50 \mathrm{~dB})$ replacing PORP with different materials $(50 \mathrm{~dB})$
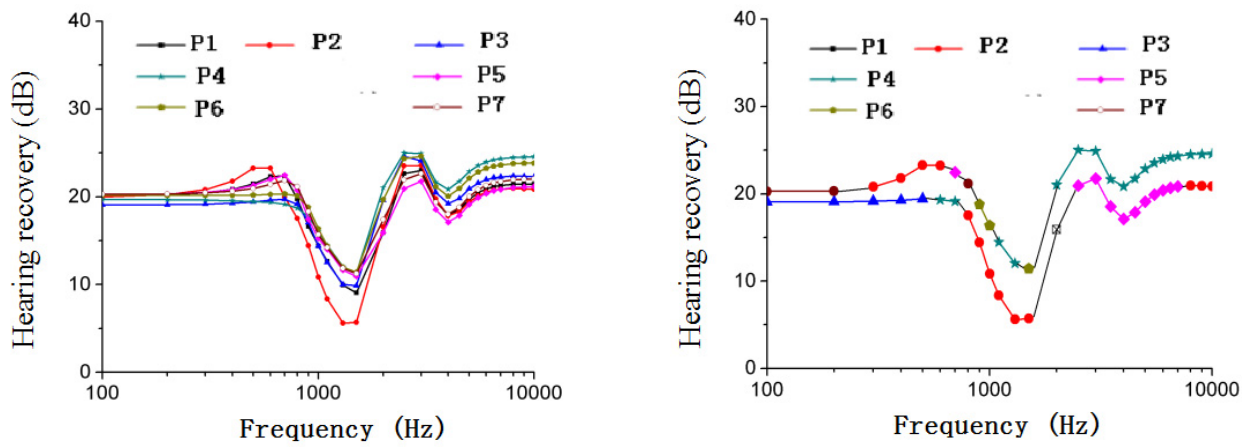

Fig. 21. Diagram for hearing recovery after replacing Fig. 22. Envelop diagram for hearing recovery after PORP with different materials $(105 \mathrm{~dB})$ replacing PORP with different materials $(105 \mathrm{~dB})$
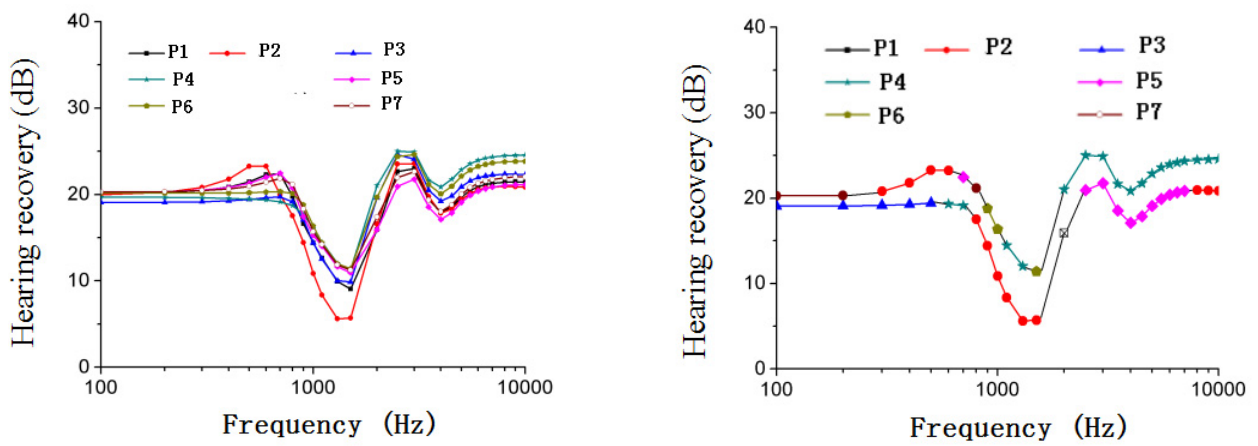

Fig. 23. Diagram for hearing recovery after replacing Fig. 24. Envelop diagram for hearing recovery after PORP with different materials $(120 \mathrm{~dB})$ replacing PORP with different materials $(120 \mathrm{~dB})$ 

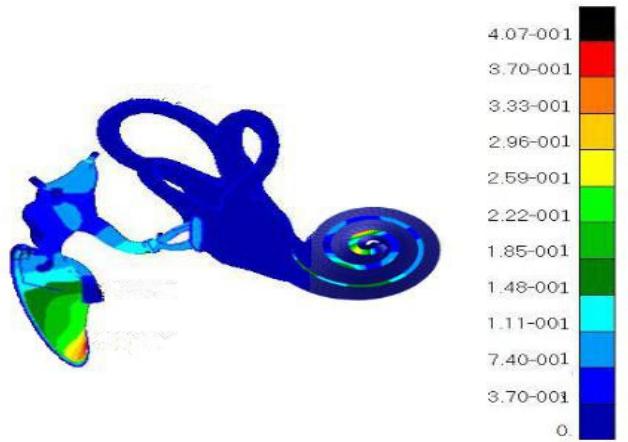

Fig. 25. The vibration response of the whole ear after replacing PORP $(120 \mathrm{~dB})$

Table 7. The maximum value of postoperative hearing recovery after replacing PORP

\begin{tabular}{|c|c|c|c|c|c|}
\hline $\begin{array}{c}\text { Frequency } \\
(\mathrm{Hz})\end{array}$ & $\begin{array}{c}\text { Material with the } \\
\text { maximum hearing } \\
\text { recovery }\end{array}$ & $\begin{array}{c}\text { The maximum } \\
\text { interval under } \\
50 \mathrm{~dB} \text { SPL }\end{array}$ & $\begin{array}{c}\text { The maximum } \\
\text { interval under } \\
80 \mathrm{~dB} \text { SPL }\end{array}$ & $\begin{array}{c}\text { The maximum } \\
\text { interval under } \\
105 \mathrm{~dB} \text { SPL }\end{array}$ & $\begin{array}{c}\text { The maximum } \\
\text { interval under } \\
120 \mathrm{~dB} \text { SPL }\end{array}$ \\
\hline $100-200$ & $\begin{array}{c}\text { Hydroxyapatite } \\
\text { ceramics }\end{array}$ & $20.28-20.33$ & $20.27-20.33$ & $20.28-20.33$ & $20.29-20.33$ \\
\hline $200-600$ & Stainless steel & $20.79-23.25$ & $20.33-23.26$ & $20.79-23.26$ & $20.92-23.26$ \\
\hline $600-700$ & Alumina ceramic & $22.01-22.46$ & $22.46-23.25$ & $22.00-23.26$ & $21.80-23.27$ \\
\hline $700-800$ & $\begin{array}{c}\text { Hydroxyapatite } \\
\text { ceramics }\end{array}$ & $21.17-21.86$ & $21.17-22.46$ & $21.17-21.86$ & $21.15-21.83$ \\
\hline $800-1000$ & EH type composites & $16.34-21.11$ & $16.34-21.17$ & $16.33-20.11$ & $16.44-20.01$ \\
\hline $1000-10000$ & Porous polyethylene & $11.32-25.02$ & $12.04-25.00$ & $11.32-25.02$ & $11.35-25.12$ \\
\hline
\end{tabular}

Table 8. The minimum value of postoperative hearing recovery after replacing PORP

\begin{tabular}{|c|c|c|c|c|c|}
\hline $\begin{array}{c}\text { Frequency } \\
(\mathrm{Hz})\end{array}$ & $\begin{array}{c}\text { Material with the } \\
\text { minimum } \\
\text { hearing recovery }\end{array}$ & $\begin{array}{c}\text { The minimum } \\
\text { interval under } \\
50 \mathrm{~dB} \text { SPL }\end{array}$ & $\begin{array}{c}\text { The minimum } \\
\text { interval under } \\
\text { 80 dB SPL }\end{array}$ & $\begin{array}{c}\text { The minimum } \\
\text { interval under } \\
\text { 105 dB SPL }\end{array}$ & $\begin{array}{c}\text { The minimum } \\
\text { interval under } \\
120 \mathrm{~dB} \text { SPL }\end{array}$ \\
\hline $100-500$ & Teflon & $19.06-19.42$ & $19.06-19.42$ & $19.06-19.43$ & $19.07-19.45$ \\
\hline $500-700$ & $\begin{array}{c}\text { Porous } \\
\text { polyethylene }\end{array}$ & $19.14-19.47$ & $19.14-19.42$ & $19.14-19.47$ & $19.16-19.49$ \\
\hline $700-1500$ & Stainless steel & $5.62-19.99$ & $5.62-19.14$ & $5.70-19.99$ & $5.68-19.96$ \\
\hline 2000 & Titanium & 15.89 & 15.90 & 15.91 & 15.92 \\
\hline $2500-8000$ & Alumina ceramic & $17.11-20.75$ & $17.10-20.70$ & $17.12-21.75$ & $17.14-21.79$ \\
\hline $8000-10000$ & Stainless steel & $20.83-20.94$ & $20.70-21.36$ & $20.84-20.96$ & $20.86-20.98$ \\
\hline
\end{tabular}

However, artificial auditory ossicle with teflon and porous polyethylene had the minimum hearing recovery, about $5.62 \mathrm{~dB}$ to $19.47 \mathrm{~dB}$ at low frequencies. At high frequencies, artificial auditory ossicle with porous polyethylene improved human ear hearing most, namely $11.32 \mathrm{~dB}$ to $25.02 \mathrm{~dB}$, and reached the maximum value about $25.02 \mathrm{~dB}$ around $3000 \mathrm{~Hz}$. However, artificial auditory ossicle with alumina ceramic and stainless steel had the minimum hearing recovery at high frequencies, about $15.89 \mathrm{~dB}$ to $21.75 \mathrm{~dB}$. Only postoperative hearing recovery in short term could be analyzed through the finite element. In addition, the artificial auditory ossicle with different materials had a good effect on the hearing recovery of human ear in short term. Artificial auditory ossicle with hydroxyapatite ceramics, stainless steel and alumina ceramic had a good effect on sound conduction at low frequencies. Artificial auditory ossicle with porous polyethylene and teflon had a good effect on sound conduction at high frequencies. With considering hearing effect in long term, titanium, teflon and hydroxyapatite ceramic which possessed the best biocompatibility would have better hearing effect.

The first author has completed this paper from the beginning to the end, the second author has provided the idea, the third author has completed the translation, and the other authors have checked this paper and submitted it to the submission system. 


\section{Conclusions}

This paper constructed a complete three-dimensional finite element model of human ear, combined with NASTRAN software to analyze frequency response and qualitatively and quantitatively studied and compared the influence of PORP with 7 kinds of materials on the sound conduction of human ear under different sound pressures $(50 \mathrm{~dB}, 80 \mathrm{~dB}, 105 \mathrm{~dB}$ and $120 \mathrm{~dB})$ at $100 \mathrm{~Hz}-10000 \mathrm{~Hz}$ and the postoperative hearing recovery. Results showed that the postoperative hearing recovery of human ear had the same effect after replacing PORP under different sound pressures with the same frequency. At different frequency bands with the same sound pressure, the postoperative hearing recovery of human ear had the same effect after replacing PORP with different materials. Artificial auditory ossicle with hydroxyapatite ceramics, stainless steel and alumina ceramic had a better effect on sound conduction at low frequencies. Artificial auditory ossicle with porous polyethylene and teflon had a better effect on sound conduction at high frequencies. With considering the hearing effect in long term, titanium, teflon and hydroxyapatite ceramics which possessed the best biocompatibility would have better long-term hearing effect. Under different sound pressures, the hearing recovery values of human ear had little difference at each frequency band after replacing PORP with different materials, which indicated that PORP with different materials had a stable influence on the sound conduction of human ear under the excitation of different sound pressures.

This paper applied 7 kinds of common materials to artificial auditory ossicle and analyzed their influences on the postoperative hearing effect of middle ear only from the perspective of physic-mechanical property. However, this paper did not analyze the reason for different influences caused by artificial auditory ossicle with 7 kinds of common materials and the issue of their biocompatibility from the perspective of material microscopic property. It will be further expanded in the future studies.

In recent years, material science has developed rapidly and nanometer material technology has become a new field which scientists pay attention to. The characteristics of nanometer materials including surface and interface effect, small-size effect, quantum size effect and so on may make the replaced structure and bone tissues directly form firm biological bonding. If artificial auditory ossicle structure is made of biological nanometer material, artificial auditory ossicle will be likely to have better biocompatibility, superior performance and postoperative stability in long term.

\section{References}

[1] Sunil Puria, et al. Measurements of human middle ear forward and reverse acoustics: Implications for otoacoustic emissions. Journal of the Acoustical Society of America, Vol. 113, Issue 5, 2003, p. 2773-2789.

[2] Willi Urban B. Middle-ear Mechanics: The Dynamic Behavior of the Incudo-Malleolar Joint and its Role During the Transmission of Sound. Ph.D. Thesis, 2003.

[3] Kelly D. J., Prendergast P. J., Blayney A. W. The effect of prosthesis design on vibration of the reconstructed ossicular chain: a comparative finite element analysis of four prosthe-se. Otology and Neurotology, Vol. 24, 2003, p. 11-19.

[4] Unur Erdoğan, Ülger Harun, Ekinci Nihat Morphometrical and morphological variations of middle ear ossicles in the newborn. Erciyes Tip Dergisi (Erciyes Medical Journal), Vol. 24, Issue 2, 2002, p. $57-63$.

[5] Gan R. Z., Feng B., Sun Q. Three-dimensional finite element modeling of human ear for sound transmission. Annals of Biomedical Engineering, Vol. 32, Issue 6, 2004, p. 847-859.

[6] Reza Masteri Farahani, Mehrdad Nooranipour Anatomy and anthropometry of human stapes. American Journal of Otolaryngology-Head and Neck Medicine and Surgery, Vol. 29, Issue 1, 2008, p. $42-47$.

[7] Rolf Quam, Yoel Rak Auditory ossicles from southwest Asian Mousterian sites. Journal of Human Evolution, Vol. 54, Issue 1, 2008, p. 414-433.

[8] Pozrikidis C. Boundary-integral modeling of cochlear hydrodynamics. Journal of Fluids and Structures, Vol. 24, Issue 1, 2008, p. 336-365. 
[9] Molnarka G., Miletics E. M., Fiicsek M. A mathematical model for the middle ear ventilation. American Institute of Physics, 2008, p. 106-109.

[10] Lu Hongbing, Luo Huiyang, Dai Chenkai, Gan Rong Z. The Young's modulus of human eardrum at high strain rates. 11th International Congress and Exhibition on Experimental and Applied Mechanics, Society for Experimental Mechanics, Vol. 2, Issue 1, 2008, p. 896-899.

[11] Daphalapurkar Nitin P., Dai Chenkai, Gan Rong Z., Lu Hongbing Characterization of the linearly viscoelastic behavior of human tympanic membrane by nanoindentation. Journal of the Mechanical Behavior of Biomedical Materials, Vol. 2, 2009, p. 82-92.

[12] Xie W., Zheng Y. Effects of hearing reconstruction by teflon prosthesis in chronic otitis media. West China Medical Journal, Vol. 25, Issue 4, 2010, p. 707-709.

[13] Zheng Y. L., Gong S. S., Yu Z. L., Li Y. X. Discussion of influencing factors on effects of ossicular chain reconstruction. Chinese Archives of Otolaryngology-Head and Neck Surgery, Vol. 17, Issue 6, 2010, p. 291-293.

[14] Chen Y., Han Y., Lu L. J., Qiu J. H. The contrastive analysis of 60 cases of ossicular chain reconstruction using different replacement prostheses. Chinese Journal of Otology, Vol. 8, Issue 3, 2010, p. 240-243.

[15] Huang Z. Y., Zhou F. H., Xie N. P., Guo M. H., Wan L. C., Sun W. Q. Therapeutic effect of ossicular reconstruction with bioceramic or porous macromolecular polyethylene partial ossicular replacement prosthesis in patients with tympanosclerosis. Journal of Southern Medical University, Vol. 30, Issue 9, 2010, p. 2181-2184.

[16] Zhang G. P., Wu A. X., Li Y. Q., Han Z. L., Gui T. Analysis of short-tern clinical effect of bioceramic and titanium ossicular. Chinese Journal of Otology, Vol. 5, Issue 2, 2007, p. 136-140.

[17] Zeng L. G., Li J. P. Biocompatibility and application of artificial ossicular chain reconstruction materials. Journal of Clinical Rehabilitative Tissue Engineering Research, Vol. 11, Issue 48, 2007, p. 9789-9792.

[18] Zhang X. M., Gan R. Z. Finite element modeling of energy absorbance in normal and disordered human ears. Hearing Research, Vol. 301, 2013, p. 146-155.

[19] Yao W. J. Advance in biomechanics of human ear as hearing system. Mechanics in Engineering, Vol. 35, Issue 6, 2013, p. 1-10.

[20] Wang X. L., Zhou J. J., Ling L., Hu Y. J. FE simulation of sound transmission in human ear with an active cochlea model. Journal of Vibration and Shock, Vol. 31, Issue 21, 2012, p. 41-45.

[21] Ma Jianwei, Yao Wenjuan Research of the distribution of pressure field of the basilar membrane in the passive spiral cochlea. Journal of Mechanics in Medicine and Biology, Vol. 14, Issue 4, 2014, p. $14500-14515$.

[22] Deafness and Hearing Impairment. World Health Organization Fact Sheet, 2014, http://www.who.int/mediacentre/factsheets/fs300/en/indexhtml.

[23] Yoon Y. J., Steele C. R., Puria S. Feed-forward and feed-backward amplification model from cochlear cytoarchitecture: an interspecies comparison. Biophysical Journal, Vol. 100, 2011, p. 1-10.

[24] Ferris P., Prendergast P. J. Middle-ear dynamics before and after ossicular replacement. Journal of Biomechanics, Vol. 33, 2000, p. 581-590.

[25] Huber A., Ball G., Asai M., et al. The vibration pattern of the tympanic membrane after placement of a total ossicular replacement prosthesis. Proceedings of the International Workshop on Middle Ear Mechanics in Research and Otosurgery, Dresden, 1997, p. 219-222.

[26] Nishihara N., Goode R. L. Measurement of tympanic membrane vibration in 99 human ears. Proceedings of the International Workshop on Middle Ear Mechanics in Research and Otosurgery, Dresden, 1996, p. 91-94.

[27] Dai C., Cheng T., Wood M. W., Gan R. Z. Fixation and detachment of superior and anterior malleolar ligaments in human middle ear: experiment and modeling. Hearing Research, Vol. 230, Issue 1, 2007, p. 24-33.

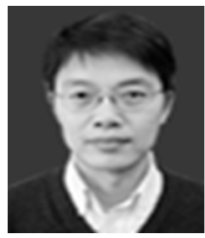

Xiaoping Jiang received his Ph.D. degree from Huazhong University of Science and Technology, China, in 2007. He is now an Associate Professor at College of Electronics and Information Engineering, South-Central University for Nationalities, Wuhan, China. His research interests include signal process, video analysis and wireless communication. 


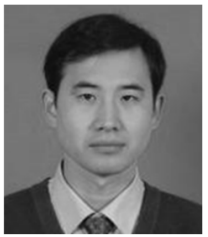

Chenghua Li was born in 1972. He received his B.S. degree, Master degree and Ph.D. degree in 1994, 2004 and 2008, respectively. He is now an Associate Professor at College of Electronics and Information Engineering, South-Central University for Nationalities, Wuhan, China. His research interests include cloud computing, image analysis and pattern recognition

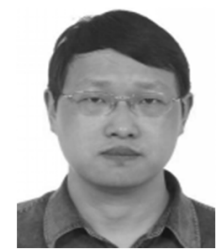

Hao Ding received Ph.D. degree from Universite De Blaise Pascal, France, in 2012. He is now a lecturer at College of Electronics and Information Engineering, South-Central University for Nationalities, Wuhan, China. His research interests include image signal processing, neural networks and compressed sensing.

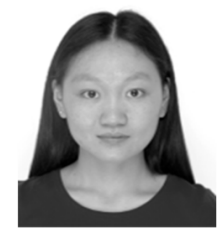

Jing Sun received her Ph.D. degree from Wuhan University, China, in 2011. She is now a lecturer at College of Electronics and Information Engineering, South-Central University for Nationalities, Wuhan, China. Her research interests include multimedia processing and multimedia security.

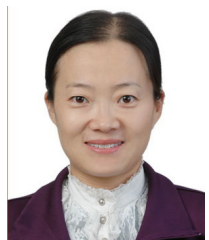

Sun Jiedi received her Ph.D. degree (2008) in precision instrument and machinery from Tianjin University. Now she is an Associate Professor in School of Information Science and Engineering, Yanshan University. Her main research interests include Blind source separation and application, complex vibration signals processing, finite element, recognition and pipeline leak detection and pre-warning system. 